\title{
Production of normal mice from spermatozoa denatured with high alkali treatment before ICSI
}

\author{
Chong $\mathrm{Li}^{1,2}$, Eiji Mizutani ${ }^{1}$, Tetsuo Ono ${ }^{1,3}$ and Teruhiko Wakayama ${ }^{1,2,3}$ \\ ${ }^{1}$ Laboratory for Genomic Reprogramming, RIKEN, Center for Developmental Biology, 2-2-3 Minatojima- \\ minamimachi, Chuo-ku, Kobe 650-0047, Japan, ${ }^{2}$ Department of Bioscience, Graduate School of Science \\ and Technology, Kwansei Gakuin University, Sanda 669-1337, Japan and ${ }^{3}$ Department of Medical Science, \\ Graduate School of Medicine, Kyoto University, Kyoto 606-8502, Japan
}

Correspondence should be addressed to C Li; Email: lichong@cdb.riken.jp

\begin{abstract}
In mammals, ICSI is now a very important tool for both assisted reproductive technology and studying the mechanisms of fertilization. In the latter experiments, it is important to use spermatozoa that have lost their oocyte activation capacity but still retain their developmental potential. In this study, we used high-concentration $\mathrm{NaOH}$ to remove oocyte activation potential from spermatozoa, and examined whether normal offspring could be generated from these spermatozoa after ICSI. The spermatozoa were treated with different concentrations of $\mathrm{NaOH}(1-100 \mathrm{mM})$ for $1 \mathrm{~h}$ and then neutralized with equal amounts of same concentration of $\mathrm{HCl}$. In $10 \mathrm{mM} \mathrm{NaOH}$ treated spermatozoa, the cell membrane was broken and most of them failed to activate oocytes after their injection into the oocytes. However, these spermatozoa did not show strong damage, and after artificial activation with $\mathrm{SrCl}_{2}$, all of the zygotes were judged as normal by immunostaining to check the methylation status of histone $\mathrm{H} 3$ lysine 9 , low chromosome damage by karyotype assay and staining with DNA double-strand breaks marker, $\gamma \mathrm{H} 2 \mathrm{AX}$. Moreover, after transferring those embryos into recipient females, 106 (36.7\%) live and healthy offspring were delivered, which is similar to the rate in the fresh control group. By contrast, spermatozoa treated with lower $\mathrm{NaOH}$ concentrations retained their oocyte activation capacity and those treated with higher concentrations lost their developmental potential. This suggests that $10 \mathrm{mM} \mathrm{NaOH}$ for $1 \mathrm{~h}$ is the best treatment to completely destroy the cell membrane and activation capacity of spermatozoa without injuring their developmental potential.

Reproduction (2009) 137 779-792
\end{abstract}

\section{Introduction}

ICSI is now a very important tool for both assisted reproductive technology and the study of fertilization, especially in mammals (Kimura \& Yanagimachi 1995a, Yanagimachi 2005). Not only intact spermatozoa but also the abnormal or artificially 'dead' spermatozoa can lead to full-term development by ICSI. Nowadays, various methods are employed to remove the plasma membrane of spermatozoa and they have been very valuable in the study of fertilization and in the further applications. Treated spermatozoa can be divided into two groups. The first group includes sonicated sperm, freeze-thawed sperm, and freeze-dried sperm which lack the plasma membrane and acrosome (Goto et al. 1990, Kuretake et al. 1996, Wakayama \& Yanagimachi 1998, Wakayama et al. 1998, Tateno et al. 2000, Kwon et al. 2004, Liu et al. 2004). These types of spermatozoa cannot complete fertilization naturally, but they do not lose their sperm-borne oocyte activating factor (SOAF), so their injection into oocytes by ICSI can lead to oocyte activation (Goto et al. 1990,
Kuretake et al. 1996, Wakayama \& Yanagimachi 1998, Wakayama et al. 1998, Tateno et al. 2000, Kwon et al. 2004, Liu et al. 2004). However, during the preparation of these samples, their nuclei are damaged, and the developmental potential of these spermatozoa after ICSI is reduced compared with that of fresh spermatozoa (Goto et al. 1990, Hoshi et al. 1995, Nagy et al. 1995, Kuretake et al. 1996, Wakayama \& Yanagimachi 1998, Ward et al. 2003).

On the other hand, the second group, heat-treated, lysolecithin (LL) and pronase treated spermatozoa or specific-stage male gametes, such as round spermatids, cannot activate oocytes after their injection into oocytes (Ogura et al. 1994, Kimura \& Yanagimachi 1995b, Cozzi et al. 2001, Jiang et al. 2005, Yan et al. 2008). If these oocytes are activated artificially, such as by $\mathrm{Sr}^{2+}$ or electrostimulation treatment (Ogura et al. 1994, Bos-Mikich et al. 1997, Yan et al. 2008), the subsequent embryos generated with these spermatozoa can support embryonic development and produce live offspring (Ogura et al. 1994, Kimura \& Yanagimachi 1995b, Cozzi et al. 2001, Kishigami et al. 2004, Jiang 
et al. 2005, Yan et al. 2008). However, for unknown reasons, the success rate of full-term offspring is significantly reduced in these compared with that of fresh spermatozoa.

The best results were obtained when spermatozoa were treated in alkyltrimethylammonium bromide (ATAB) and dithiothreitol, and then extracted with salt. These treated spermatozoa lost their cell membranes and their oocyte activation potential but did not lose their nuclear integrity, as judged by the full-term development of embryos after ICSI (Ward et al. 1999). However, this treatment is not simple, and the oocyte survival rate after ICSI was reduced, which might be attributable to the increased stickiness of the treated spermatozoa, so that ICSI does not proceed smoothly.

From these reports, it can be concluded that if spermatozoa are treated physically or chemically to remove cell components, they can easily lose not only their membrane and activation capacity but also their nuclear integrity. In other words, the treatment of spermatozoa may cause too much damage and the loss of their full-term developmental potential.

Although environmental changes can affect the normal fertilization capacity of spermatozoa, the influence of the $\mathrm{pH}$ of the medium is still unknown. Today, in in vitro culture, especially of the mouse, the $\mathrm{pH}$ of most media (such as TYH, M2, M16, CZB, and KSOM) is maintained as weakly alkaline, near 7.4 (Whittingham 1971, Quinn et al. 1982, Chatot et al. 1989, Lawitts \& Biggers 1991). It is well known that alkali solution is used to extract plasmid DNA from bacteria without injury to the DNA structure, even though the membranes of the bacteria are completely destroyed (Birnboim \& Doly 1979). Furthermore, it has been reported that for embryos generated from freeze-dried mouse spermatozoa, the best $\mathrm{pH}$ of the medium for the development to the blastocyst stage is pH 8.0-9.0 (Kaneko et al. 2003). In this weak alkaline medium, sperm nuclei can be maintained without damage. Also, some papers have reported the fertility of spermatozoa treated with high$\mathrm{pH}$ medium. It has been demonstrated in porcine systems that the treatment of sperm with $100 \mathrm{mM}$ $\mathrm{NaOH}$ in Tris-buffered saline results in the destruction of the cell membrane and failure in activating porcine oocytes. (Kim et al. 1999). It has been reported that oocyte activation after fertilization is related to phospholipase C $\zeta$ (PLC $\zeta$; Parrington et al. 2002). PLC $\zeta$ has been identified as an important spermatozoan factor that activates the development of the embryo (Saunders et al. 2002, Swann et al. 2006). The reason why an alkaline medium abolishes the activation potential of spermatozoa is that the high-pH treatment inhibits PLC $\zeta$, resulting in abrogation of the $\mathrm{Ca}^{2+}$ oscillation in oocyte (Kurokawa et al. 2005). However, the nuclear integrity of spermatozoa under this condition is still unclear. Moreover, there has been no report of the effects on embryo development when the injected spermatozoa have been treated with extremely high-pH medium, and no live offspring have been reported using such spermatozoa.

In this study, we examined spermatozoal fertility and nuclear integrity after treating with highly alkaline medium. The sperm were treated with different concentrations of $\mathrm{NaOH}$ solution $(1-100 \mathrm{mM})$ for $1 \mathrm{~h}$. The morphological changes and vitality of the $\mathrm{NaOH}$-treated spermatozoa were analyzed by live/dead assay, transmission electron microscopy (TEM), acridine orange (AO) staining, and the TUNEL assay. The oocyte activation potential of $\mathrm{NaOH}$-treated spermatozoa was investigated by ICSI. The normality of male pronuclei in zygotes was examined by immunostaining of histone $\mathrm{H} 2 \mathrm{AX}$ phosphorylation at serine $139(\gamma \mathrm{H} 2 \mathrm{AX})$, which is a DNA double strand breaks (DSBs) marker, and karyotype analysis after artificial activation. Finally, the nuclear integrity of $\mathrm{NaOH}$-treated spermatozoa was demonstrated by the production of healthy offspring after embryo transfer into recipient females. These results showed that a suitably high $\mathrm{pH}$ can destroy both the plasma membrane and oocyte activation factors but does not injure the spermatozoal nucleus in terms of full-term embryonic development. From these results, we suggest that $\mathrm{NaOH}$ treatment is a simple method of spermatozoal pretreatment, and that these spermatozoa can be widely used in future research, investigating issues such as oocyte activation, sperm preservation, and transgenesis.

\section{Results}

\section{Morphology and vitality of $\mathrm{NaOH}$-treated spermatozoa}

Although it has been reported that highly alkaline medium can inhibit the oocyte activation of porcine spermatozoa (Kim et al. 1999, Kurokawa et al. 2005), it is still unclear whether high $\mathrm{pH}$ values affect the morphology of spermatozoa. First, epididymal spermatozoa were treated with different concentrations of $\mathrm{NaOH}(1-100 \mathrm{mM})$ for $1 \mathrm{~h}$. All the spermatozoa treated with $\mathrm{NaOH}$ lost their motility. Using the live/ dead assay, we showed that $42.8 \%$ of the fresh spermatozoa and $100 \%$ of the $\mathrm{NaOH}$-treated spermatozoa were biologically 'dead' (Fig. $1 \mathrm{e}-\mathrm{h}, n=3$ ). Next, to analyze the damage to the spermatozoa in detail, TEM was used to observe sagittal sections of the sperm heads after $\mathrm{NaOH}$ treatment. Only $13 \%$ of the fresh spermatozoa showed a dissolved membrane, and the acrosome was invisible in $6 \%$ of them (Fig. 1i). However, these rates were 43 and $65 \%$ respectively, in $1 \mathrm{mM} \mathrm{NaOH}$-treated spermatozoa; 100 and $80 \%$ respectively, in $10 \mathrm{mM} \mathrm{NaOH}$-treated spermatozoa (Fig. $1 \mathrm{j}$ and k); and 100 and $100 \%$ respectively, in $100 \mathrm{mM} \mathrm{NaOH}$-treated spermatozoa (Fig. 1l). Importantly, in spermatozoa treated with $10 \mathrm{mM}$ 

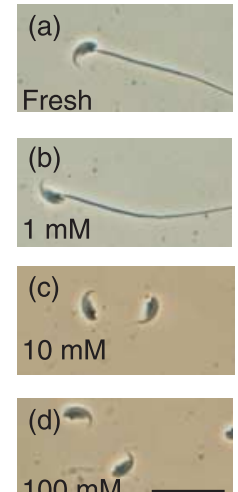

$100 \mathrm{mM}$
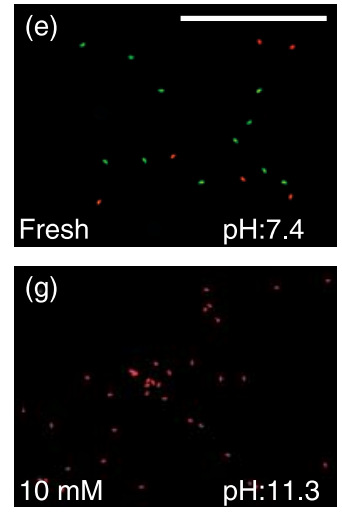
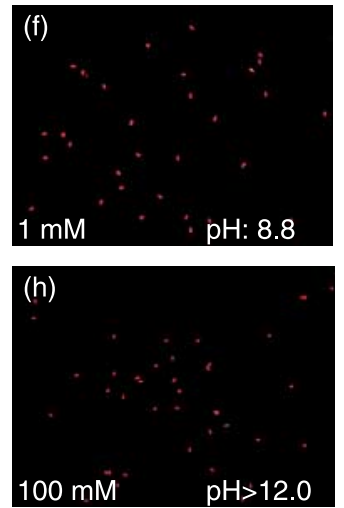
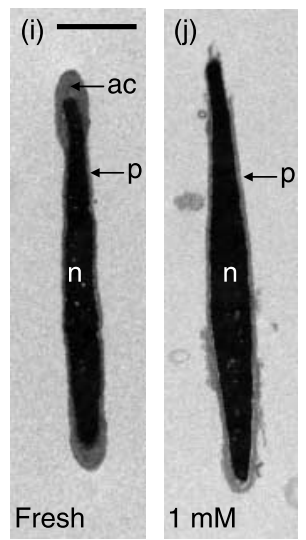
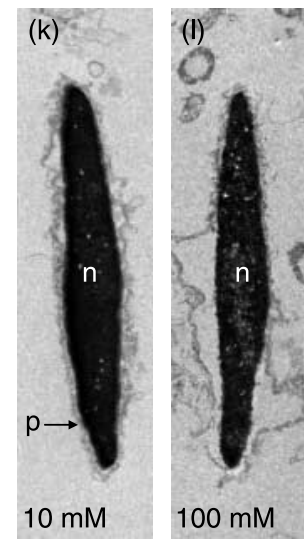

Figure 1 Vitality and morphological alteration of spermatozoa after $\mathrm{NaOH}$ treatment. (a-d) The morphology of normal and $\mathrm{NaOH}$-treated spermatozoa. (a) Fresh spermatozoa; (b) $1 \mathrm{mM} \mathrm{NaOH}$-treated spermatozoa; (c) $10 \mathrm{mM} \mathrm{NaOH}$-treated spermatozoa; (d) $100 \mathrm{mM} \mathrm{NaOH}$-treated spermatozoa. Note that in (c) and (d), in spermatozoa treated with stronger $\mathrm{NaOH}$, the head is separated from the tail. (a-d, scale bar $=20 \mu \mathrm{m}$ ). (e-h) The $\mathrm{pH}$ of the medium and the vitality of the $\mathrm{NaOH}$-treated spermatozoa assessed with the live/dead assay. Green fluorescence shows living spermatozoa, and red fluorescence shows dead spermatozoa. (e) Living spermatozoa constituted $57.2 \%$ of the fresh control group. However, all $\mathrm{NaOH}$-treated spermatozoa were dead: (f) $1 \mathrm{mM} \mathrm{NaOH}$-treated, (g) $10 \mathrm{mM} \mathrm{NaOH}$-treated and (h) $100 \mathrm{mM} \mathrm{NaOH}$-treated (e-h, scale bar $=200 \mu \mathrm{m}$ ). (i-l) TEM images of spermatozoa heads after $\mathrm{NaOH}$ treatment. (i) The normal spermatozoa structure, with the plasma membrane and acromosome; ( $\mathrm{j}-\mathrm{l}$ ) after $\mathrm{NaOH}$ treatment, the plasma membrane and acromosome were invisible: (i) $1 \mathrm{mM} \mathrm{NaOH}$-treated spermatozoa, (k) $10 \mathrm{mM}$ $\mathrm{NaOH}$-treated spermatozoa and (l) $100 \mathrm{mM} \mathrm{NaOH}$-treated spermatozoa (scale bar $=1 \mu \mathrm{m}$ ). ac, acrosome; $p$, plasma membrane; and $\mathrm{n}$, nucleus.

$\mathrm{NaOH}$ or stronger, the tails of most spermatozoa had detached from the heads (Fig. 1c and d), which made it easier to compare them with the tail-bearing intact fresh spermatozoa in ICSI.

\section{Activation capacity of $\mathrm{NaOH}$-treated spermatozoa after ICSI}

To determine whether the spermatozoa treated with alkaline medium maintained their activation capacity, $\mathrm{NaOH}$-treated spermatozoa were injected into MII oocytes using ICSI. As shown in Table 1, $1 \mathrm{mM} \mathrm{NaOH}-$ treated spermatozoa retained their oocyte activation potential, and most of the oocytes were activated after ICSI. However, the development rate to morula/blastocyst $(\mathrm{M} / \mathrm{B})$ stage was reduced $(44 \%)$ compared with that of the control group (76.5\%). Immunostaining showed that the zygotes fertilized by $1 \mathrm{mM} \mathrm{NaOH}-$ treated spermatozoa had normal $\mathrm{H} 3 \mathrm{~K} 9$ methylation status at both 6 and $24 \mathrm{~h}$ after ICSI (Fig. 2Aa-b" and $\left.\mathrm{Ba}-\mathrm{b}^{\prime \prime}\right)$. However, $10 \mathrm{mM}$ or stronger $\mathrm{NaOH}$-treated spermatozoa lost their oocyte activation potential because most of the injected oocytes did not form either male or female pronuclei (Fig. 2Ac-e ${ }^{\prime \prime}$ ). The spindles derived from the sperm nuclei were clearly visible in these injected oocytes, even $24 \mathrm{~h}$ after ICSI (Fig. 2Bc-e $\mathrm{e}^{\prime \prime}$ ). This result is comparable with that of the heat-shock experiment described previously (Cozzi et al. 2001), in which the heat-treated spermatozoa had a morphology similar to that of the $\mathrm{NaOH}$-treated spermatozoa.

\section{In vitro development after artificial activation of $\mathrm{NaOH}$-treated spermatozoa injected oocytes}

It is well known that calcium-free medium containing strontium can activate oocytes, and that the resultant embryo fertilized with a defective sperm, such as a heattreated spermatozoon or round spermatid (Ogura et al. 1994, Kimura \& Yanagimachi 1995b, Cozzi et al. 2001), can develop to full-term. Therefore, we artificially activated oocytes to determine whether oocytes injected with $\mathrm{NaOH}$-treated spermatozoa could develop normally. In all the $\mathrm{NaOH}$-treated spermatozoa groups, most embryos formed male and female pronuclei following activation with $\mathrm{Sr}^{2+}$ for $1 \mathrm{~h}$ (Table 2). Immunostaining showed normal pronucleus formation

Table 1 Embryonic development after ICSI with $\mathrm{NaOH}$-treated spermatozoa.

\begin{tabular}{lllll}
\hline Medium & $\begin{array}{l}\text { No. of oocytes } \\
\text { survived (no. of replicates) }\end{array}$ & $\begin{array}{l}\text { No. of oocytes } \\
\text { activated }(\%)^{\mathbf{a}}\end{array}$ & $\begin{array}{l}\text { No. of two-cell } \\
\text { embryos }(\%)^{\mathrm{a}}\end{array}$ & $\begin{array}{c}\text { No. of morula/ } \\
\text { blastocysts }(\%)^{\mathbf{a}}\end{array}$ \\
\hline $\mathrm{HEPES}-\mathrm{CZB}$ & $68(5)$ & $67(98.5)$ & $64(94.1)$ & $52(76.5)$ \\
$1 \mathrm{mM} \mathrm{NaOH}$ & $95(5)$ & $83(87.4)$ & $79(83.2)$ & $42(44.2)$ \\
$10 \mathrm{mM} \mathrm{NaOH}$ & $91(5)$ & $3(3.3)$ & $3(3.3)$ & $2(2.2)$ \\
$20 \mathrm{mM} \mathrm{NaOH}$ & $81(5)$ & 0 & 0 & 0 \\
$50 \mathrm{mM} \mathrm{NaOH}$ & $70(5)$ & $1(1.4)$ & $1(1.4)$ & $1(1.4)$ \\
\hline
\end{tabular}

${ }^{\mathrm{a} C o m p a r e d}$ with surviving oocytes. 


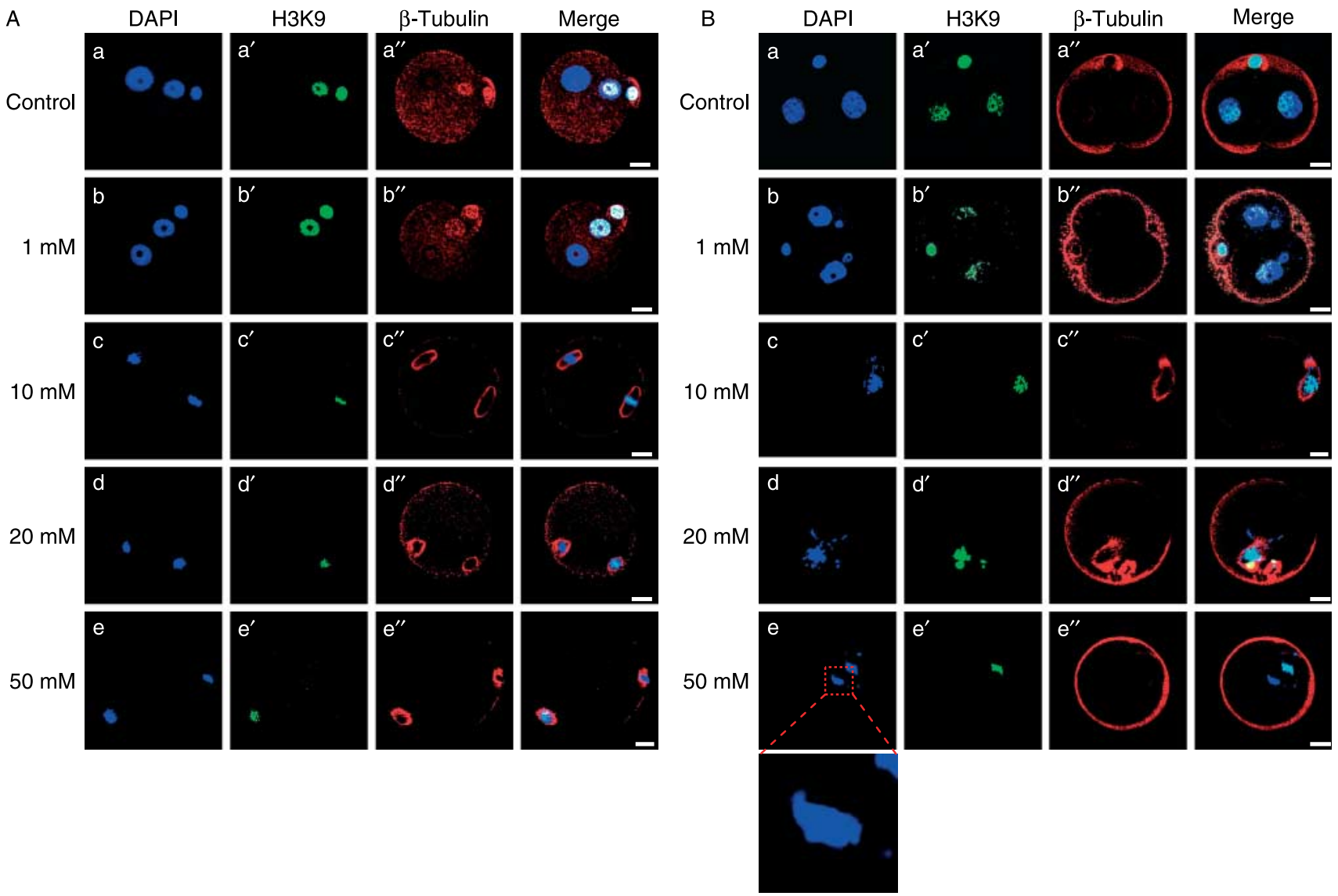

Figure 2 Pronuclei formation and embryonic development check after injection of $\mathrm{NaOH}$-treated spermatozoa by immunostaining. (A) Six hours after injection. (a-e $\left.\mathrm{e}^{\prime \prime}\right)$ Zygotes were stained for $\mathrm{H} 3 \mathrm{~K} 9 \mathrm{me} 3, \beta$-tubulin and with DAPI at the pronucleus stage. (a-e) Pronuclei were stained with DAPI. $\left(a^{\prime}-e^{\prime}\right)$ Female pronuclei stained brightly for H3K9me3. $\left(a^{\prime \prime}-e^{\prime \prime}\right)$ Staining for $\beta$-tubulin. Spindles are clearly visible in $\left(c^{\prime \prime}-e^{\prime \prime}\right)$. (a) Oocytes were microinjected with fresh spermatozoa $(n=62)$; (b) with $1 \mathrm{mM} \mathrm{NaOH}$-treated spermatozoa ( $n=30$ ); (c) with $10 \mathrm{mM} \mathrm{NaOH}$-treated spermatozoa $(n=74)$; (d) with $20 \mathrm{mM} \mathrm{NaOH}$-treated spermatozoa $(n=20)$; and (e) with $50 \mathrm{mM} \mathrm{NaOH}$-treated spermatozoa $(n=20)$. a-e $\mathrm{e}^{\prime \prime}, \mathrm{scale}$ bar $=20 \mu \mathrm{m}$. (B) Twenty-four hours after injection. (a- $\mathrm{e}^{\prime \prime}$ ) In vitro development of zygotes at the two-cell stage. (a-e) Nuclei were stained with DAPI. Enlargement of (e) shows the remaining spermatozoal head $24 \mathrm{~h}$ after ICSI. $\left(\mathrm{a}^{\prime}-\mathrm{e}^{\prime}\right)$ Stained for H3K9me3. Only female-derived chromatin stained for H3K9me3. $\left(a^{\prime \prime}-e^{\prime \prime}\right) \beta$-Tubulin-directed staining of the cytoskeleton. In normal embryonic development, $\beta$-tubulin is located at the cell membrane $\left(a^{\prime \prime}, b^{\prime \prime}\right)$, whereas in arrested zygotes, $\beta$-tubulin is still observed surrounding the nucleus ( $\left.\mathrm{c}^{\prime \prime}-\mathrm{e}^{\prime \prime}\right)$. (a) ICSI using fresh spermatozoa $(n=13)$; (b) $1 \mathrm{mM}$ $\mathrm{NaOH}$-treated spermatozoa ( $n=17)$; (c) $10 \mathrm{mM} \mathrm{NaOH}$-treated spermatozoa $(n=35)$; (d) $20 \mathrm{mM} \mathrm{NaOH}$-treated spermatozoa $(n=13)$ and (e) $50 \mathrm{mM}$ $\mathrm{NaOH}$-treated spermatozoa $(n=15)$. a-e $\mathrm{e}^{\prime \prime}$, scale bar $=20 \mu \mathrm{m}$.

and the normal methylation status of H3K9 in all groups (Fig. 3a-e $\left.\mathrm{e}^{\prime \prime}\right)$. However, the in vitro development rate was quite different in each group. Although a slight reduction occurred, there was no significant difference between fresh, $1 \mathrm{mM} \mathrm{NaOH}$-treated, and $10 \mathrm{mM} \mathrm{NaOH}$-treated spermatozoa at the two-cell stage or the M/B stage (88.8-99.2 and $67.4-83.5 \%$ respectively). However, the oocytes injected with spermatozoa treated with higher $\mathrm{NaOH}$ concentrations (20 or $50 \mathrm{mM}$ ) showed a low developmental rate at both the two-cell and M/B stages (63.4-7.7 and 30.5-0\% respectively).

Because artificial activation can lead to the parthenogenetic development of oocytes without a male genome, it is necessary to examine whether those

Table 2 In vitro development after artificial activation.

\begin{tabular}{lccrr}
\hline Medium & $\begin{array}{l}\text { No. of oocytes survived } \\
(\text { no. of replicates) }\end{array}$ & $\begin{array}{l}\text { No. of oocytes } \\
\text { activated }(\%)^{a}\end{array}$ & $\begin{array}{l}\text { No. of two-cell } \\
\text { embryos }(\%)^{a}\end{array}$ & $\begin{array}{l}\text { No. of morula/ } \\
\text { blastocysts }(\%)^{a}\end{array}$ \\
\hline HEPES-CZB & $122(5)$ & $121(99.2)$ & $120(99.2)$ & $101(83.5)$ \\
$1 \mathrm{mM} \mathrm{NaOH}$ & $67(4)$ & $67(100)$ & $61(91.0)$ & $48(71.6)$ \\
$10 \mathrm{mM} \mathrm{NaOH}$ & $89(4)$ & $89(100)$ & $59(88.8)$ & $60(67.4)$ \\
$20 \mathrm{mM} \mathrm{NaOH}$ & $85(4)$ & $82(96.5)$ & $6(63.4)$ & $25(30.5)$ \\
$50 \mathrm{mM} \mathrm{NaOH}$ & $81(5)$ & $78(96.3)$ & 0 & 0 \\
\hline
\end{tabular}

${ }^{\mathrm{a} C}$ Compared with surviving oocytes. 

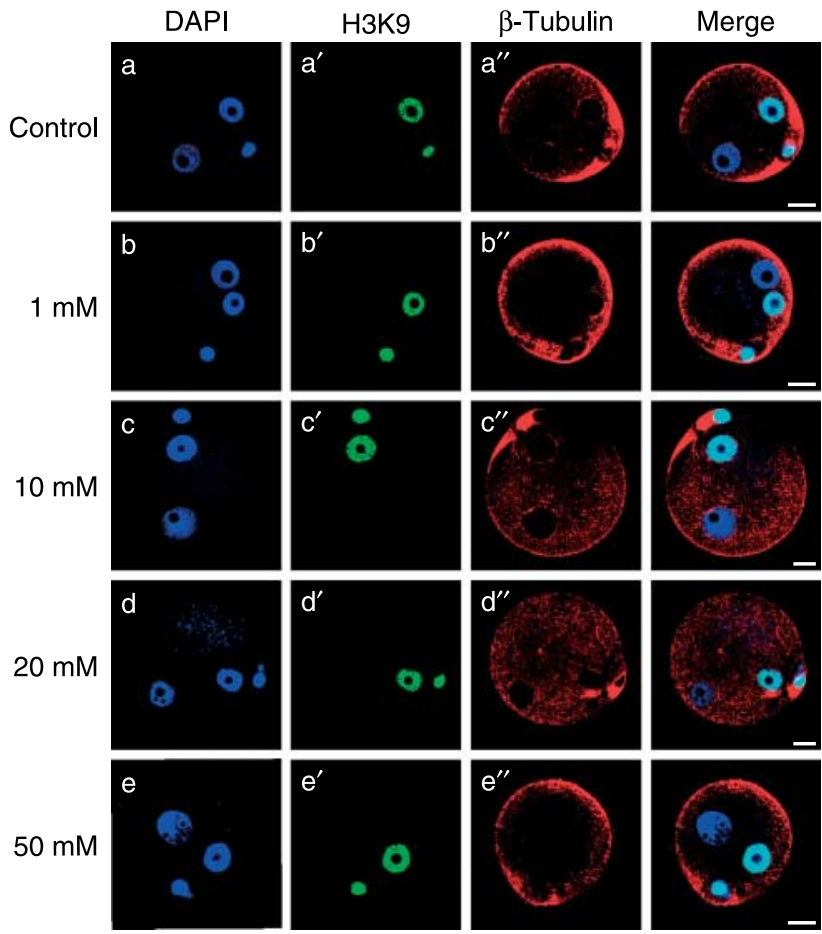

Figure 3 Pronucleus formation in zygotes obtained by ICSI with $\mathrm{NaOH}$ treated spermatozoa followed by artificial activation. Pronucleus formation $6 \mathrm{~h}$ after ICSI following injection of artificially activated $\mathrm{NaOH}$-treated spermatozoa $\left(\mathrm{a}-\mathrm{e}^{\prime \prime}\right)$. (a-e) DAPI staining of pronuclei; $\left(a^{\prime}-e^{\prime}\right)$ H3K9me3 staining of female pronucleus; $\left(a^{\prime \prime}-e^{\prime \prime}\right) \beta$-tubulindirected staining of the cytoskeleton. There was no significant difference between any group injected with $\mathrm{NaOH}$-treated spermatozoa (b: $1 \mathrm{mM}(n=26)$; c: $10 \mathrm{mM}(n=30)$; d: $20 \mathrm{mM}(n=21)$; e: $50 \mathrm{mM}(n=20))$ and the group injected with fresh spermatozoa $(\mathrm{a}(n=30))$. a- $\mathrm{e}^{\prime \prime}$, scale bar $=20 \mu \mathrm{m}$.

blastocysts were derived from embryos fertilized with the $\mathrm{NaOH}$-treated spermatozoa. After ICSI with $\mathrm{NaOH}$ treated green fluorescent protein (GFP) transgenic (Tg) mice-spermatozoa, $100 \%$ (26/26) of blastocysts microinjected with the $\mathrm{NaOH}$-treated GFP sperm exhibited GFP expression under u.v. light (Fig. $\left.4 a-C^{\prime}\right)$. As expected, no GFP-positive blastocysts were found in the parthenogenetic group.

\section{Influence of $\mathrm{NaOH}$ treatment of spermatozoa DNA}

Previous research has reported that spermatozoal chromosomal damage occurs in some extreme environments (Tateno et al. 2000, Ward et al. 2003, Tateno \& Kamiguchi 2004). Furthermore, in our study, fewer embryos that had been injected with $\mathrm{NaOH}$-treated spermatozoa reached the $M / B$ stage than did those injected with fresh spermatozoa. Therefore, it was necessary to analyze whether alkali treatment injures the DNA of spermatozoa. First, AO staining was used to examine the changes in spermatozoal DNA. Like fresh spermatozoa, spermatozoa treated with a lower concentration of $\mathrm{NaOH}$ had normal DNA, visible as distinct green fluorescence (Fig. 5a-c $\mathrm{c}^{\prime \prime}$ ), whereas spermatozoa treated with higher concentrations of $\mathrm{NaOH}$ displayed abnormal DNA structures, in which AO combined with single-stranded DNA (ssDNA) to produce red fluorescence (Fig. $5 \mathrm{~d}-\mathrm{e}^{\prime \prime} ; n=3$ ). DNA fragmentation was also analyzed with TUNEL. Unlike the DNaseltreated spermatozoa (positive control), none of the $\mathrm{NaOH}$-treated spermatozoa were stained by $3,3^{\prime}-$ diaminobenzidine $\left(D A B\right.$; Fig. $\left.5 f-j^{\prime}\right)$, meaning that there was no DNA fragmentation.

\section{Chromosomal abnormalities in embryos injected with $\mathrm{NaOH}$-treated spermatozoa}

To examine whether chromosome damage can occur in $\mathrm{NaOH}$-treated spermatozoa, karyotypes were analyzed $20 \mathrm{~h}$ after ICSI, when the zygotes were treated with vinblastine to inhibit the first mitotic cleavage. As shown in Table 3, over $80 \%$ of fresh-spermatozoa-injected zygotes had normal chromosomes. However, in those injected with $\mathrm{NaOH}$-treated spermatozoa, the rate of abnormal chromosomes increased to $52 \%$ for $1 \mathrm{mM}$ $\mathrm{NaOH}$ - and 33\% for $10 \mathrm{mM} \mathrm{NaOH}$-treated spermatozoa (Table 3 and Fig. 6). Moreover, most karyotypes showed abnormalities after 20 and $50 \mathrm{mM} \mathrm{NaOH}$ treatments (Table 3). Freeze-thawed and heat-treated spermatozoa were also tested as controls. Heat-treated spermatozoa showed more severe damage (63\%) than $\mathrm{NaOH}$-treated
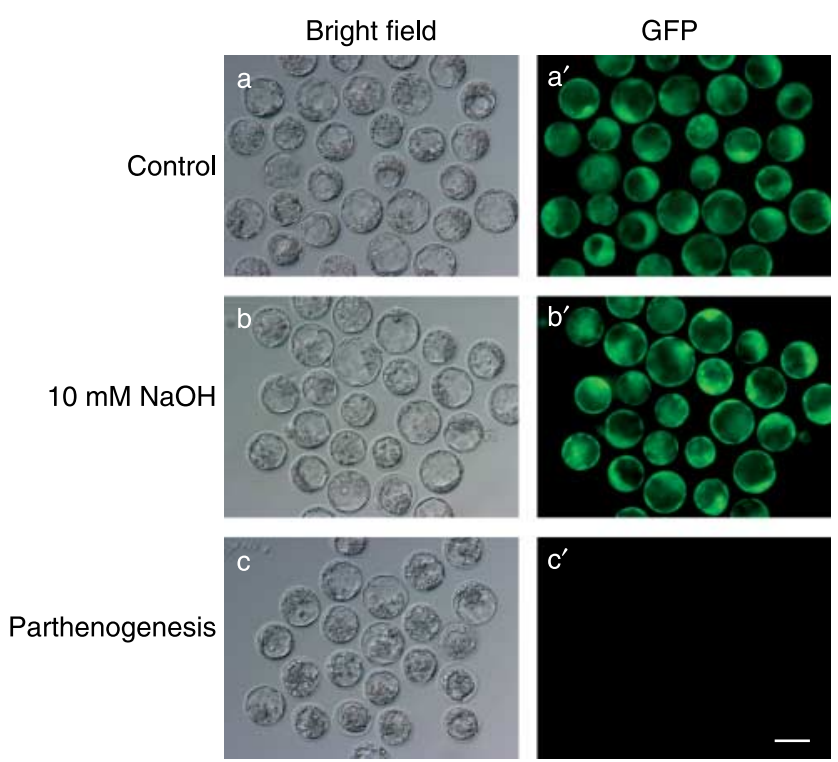

Figure 4 Comparison of blastocysts produced by ICSI with $\mathrm{NaOH}$ treated spermatozoa and parthenogenesis. $\left(\mathrm{a}-\mathrm{C}^{\prime}\right)$ In vitro development assessed with GFP transgenic ( $\mathrm{Tg}$ ) mouse spermatozoa. Embryos were observed at the blastocyst stage. $100 \%$ of $\mathrm{NaOH}$-treated $\mathrm{Tg}$ spermatozoa displayed GFP fluorescence (a and $\mathrm{a}^{\prime}$ ), as in the freshspermatozoa-injected embryos ( $b$ and $b^{\prime}$ ), whereas no fluorescence was observed in the parthenogenetic oocytes (c and $\left.c^{\prime}\right)$. a-c $c^{\prime}$, scale bar $=100 \mu \mathrm{m}$. 

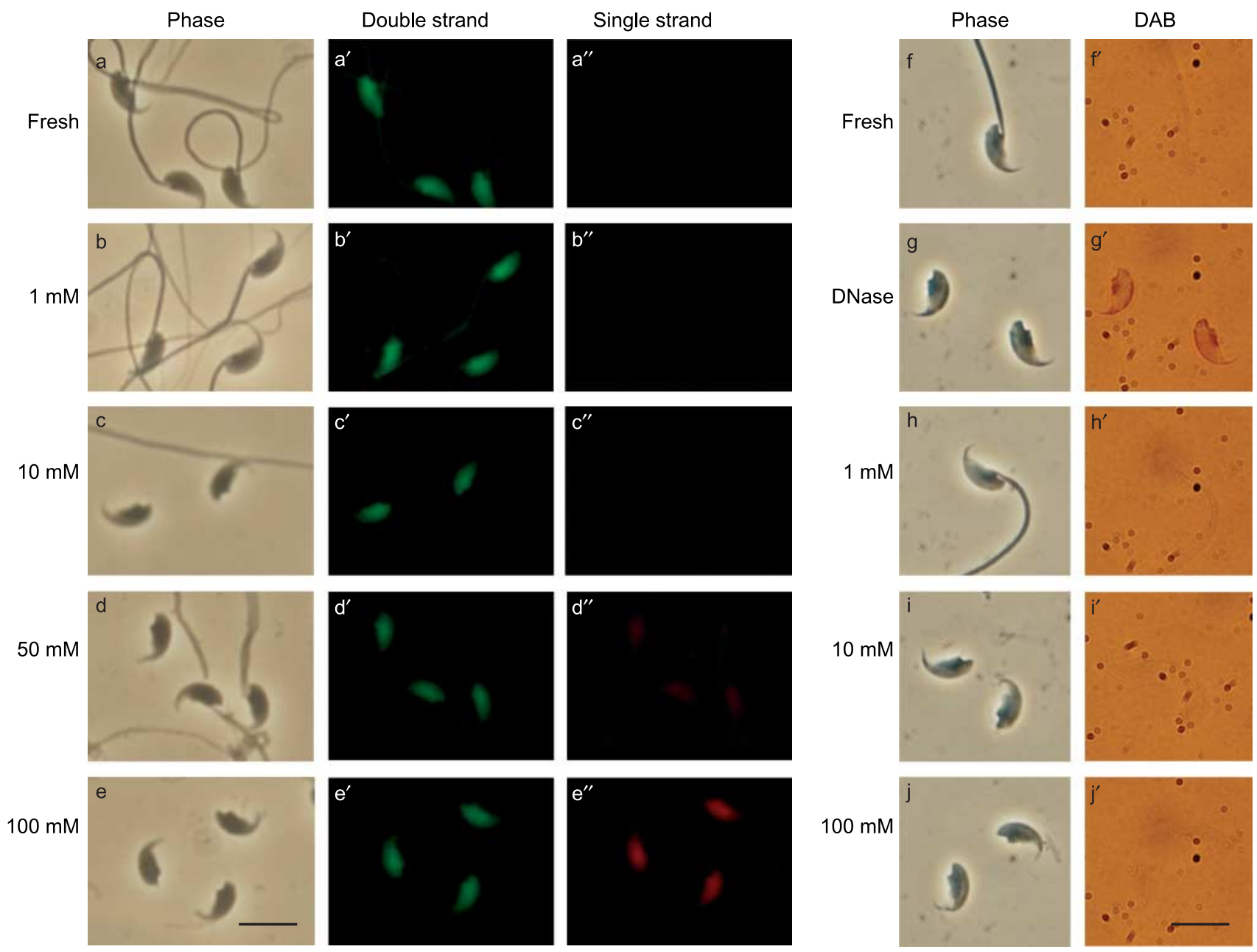

Figure 5 Chromosomal DNA damage in $\mathrm{NaOH}$-treated spermatozoa. (a-e $\left.\mathrm{e}^{\prime \prime}\right)$ Spermatozoa chromatin injury, apparent as single-stranded DNA (ssDNA) after $\mathrm{NaOH}$ treatment, visualized with $\mathrm{AO}$ stain. Normal DNA shows distinct green fluorescence, whereas the sperm head displaying red fluorescence contains ssDNA. (a-a $\left.\mathrm{a}^{\prime \prime}\right)$ Fresh spermatozoa; $\left(\mathrm{b}-\mathrm{b}^{\prime \prime}\right) 1 \mathrm{mM} \mathrm{NaOH}$-treated spermatozoa; (c-c') $10 \mathrm{mM}$ NaOH-treated spermatozoa; $\left(\mathrm{d}-\mathrm{d}^{\prime \prime}\right) 50 \mathrm{mM} \mathrm{NaOH}$-treated spermatozoa and $\left(\mathrm{e}-\mathrm{e}^{\prime \prime}\right) 100 \mathrm{mM} \mathrm{NaOH}$-treated spermatozoa. a-e $\mathrm{e}^{\prime \prime}$, scale bar=10 $\mu \mathrm{m}$. $\left(\mathrm{f}-\mathrm{j}^{\prime}\right)$ TUNEL assay for NaOHtreated spermatozoa. Fragmented spermatozoal DNA was stained with DAB. ( $\mathrm{f}$ and $\left.\mathrm{f}^{\prime}\right)$ Fresh spermatozoa; $\left(\mathrm{g}\right.$ and $\left.\mathrm{g}^{\prime}\right)$ DNasel-treated spermatozoa (positive control); (h and $\left.h^{\prime}\right) 1 \mathrm{mM} \mathrm{NaOH}$-treated spermatozoa; (i and i') $10 \mathrm{mM} \mathrm{NaOH}$-treated spermatozoa, and (j and j') $100 \mathrm{mM} \mathrm{NaOH}$-treated spermatozoa. $\mathrm{f}-\mathrm{j}^{\prime}$, scale bar $=10 \mu \mathrm{m}$.

spermatozoa, and there was no significant difference between frozen and $\mathrm{NaOH}$-treated spermatozoa. Although this result suggests that $\mathrm{NaOH}$ treatment causes more chromosomal damage than that is observed in fresh spermatozoa, it has been reported that the DNA repair mechanism can partly rescue chromosomal damage during early embryonic development (Derijck et al. 2008).

Table 3 Ratios of normal karyotypes in zygotes injected with differently treated spermatozoa.

\begin{tabular}{|c|c|c|c|c|c|}
\hline \multirow[b]{2}{*}{ Type of spermatozoa } & \multirow[b]{2}{*}{$\begin{array}{l}\text { No. of zygotes examined } \\
\text { (no. of replicates) }\end{array}$} & \multirow[b]{2}{*}{$\begin{array}{l}\text { No. of normal } \\
\text { chromosomes }(\%)\end{array}$} & \multicolumn{3}{|c|}{ No. of abnormal chromosomes of different types } \\
\hline & & & Fragment & Clump & Others $^{\mathrm{a}}$ \\
\hline Fresh & $27(4)$ & $22(81)$ & 2 & 1 & 2 \\
\hline Heat-treated & $35(4)$ & $13(37)$ & 8 & 10 & 4 \\
\hline Freeze-thawed & 47 (4) & $23(49)$ & 16 & 5 & 3 \\
\hline 1 mM NaOH & $56(5)$ & $27(48)$ & 25 & 2 & 2 \\
\hline $10 \mathrm{mM} \mathrm{NaOH}$ & $61(5)$ & $41(67)$ & 13 & 6 & 1 \\
\hline $20 \mathrm{mM} \mathrm{NaOH}$ & $45(4)$ & $12(27)$ & 14 & 13 & 5 \\
\hline $50 \mathrm{mM} \mathrm{NaOH}$ & $32(2)$ & 0 & 0 & 0 & 32 \\
\hline
\end{tabular}

${ }^{\mathrm{a}}$ Others included ring, abnormally configured, longer, and straighter chromosomes. 

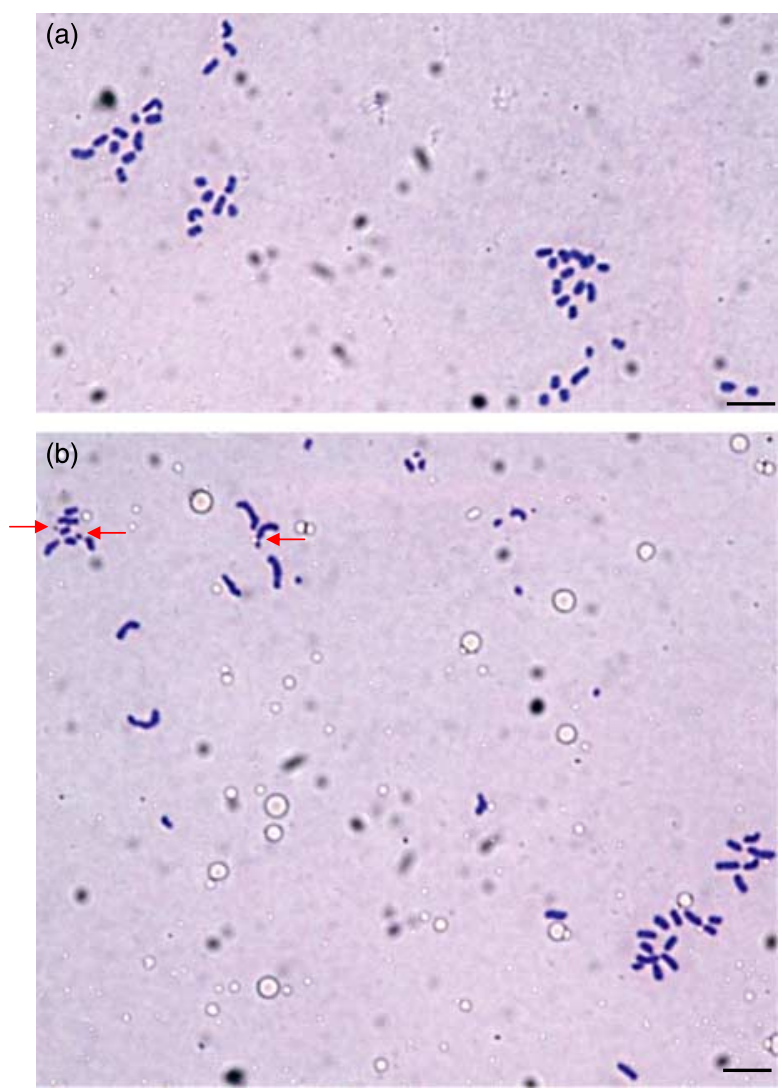

Figure 6 Karyotype analysis of zygotes obtained after ICSI with $\mathrm{NaOH}-$ treated spermatozoa. (a) Normal and (b) abnormal karyotypes of zygotes after ICSI with $10 \mathrm{mM} \mathrm{NaOH}$-treated spermatozoa. (a) Forty normal chromosomes. (b) Twenty normal chromosomes and abnormal chromosomes with visible fragmentation (arrow). Scale bar $=10 \mu \mathrm{m}$.

At the two-cell stage, DSBs were examined using immunostaining by the DSB marker $\gamma \mathrm{H} 2 \mathrm{AX}$. Embryos containing DSBs showed $\gamma \mathrm{H} 2 \mathrm{AX}$ expression, and in each group, three patterns were observed: the normal type, the 1-cell arrest type and DSBs positive type, which positively expressed $\gamma \mathrm{H} 2 \mathrm{AX}$ foci. In the fresh spermatozoa group, few DSBs positive type zygotes $(7.1 \%)$ were observed (Table 4 and Fig. $\left.7 \mathrm{a}-\mathrm{a}^{\prime \prime}\right)$, whereas a significantly higher rate of the DSBs positive type was observed in the embryos obtained with frozen $(58.3 \%)$ or heat-treated spermatozoa $(45.8 \%$; Table 4 and
Fig. $\left.7 b-c^{\prime \prime}\right)$. Although the number of DSBs expressing embryos generated from $1 \mathrm{mM} \mathrm{NaOH}-(54.5 \%)$ or $10 \mathrm{mM} \mathrm{NaOH}$-treated spermatozoa (35.9\%) was more than the number of DSBs embryos generated from fresh spermatozoa, about half the embryos were still the normal type, notably $64.1 \%$ in the $10 \mathrm{mM} \mathrm{NaOH}$ treated group (Table 4). However, embryos generated by spermatozoa treated with $20 \mathrm{mM} \mathrm{NaOH}(65.8 \%)$ and most embryos injected with $50 \mathrm{mM} \mathrm{NaOH}$-treated spermatozoa showed severe DSBs (Table 4 and Fig. $7 f-g$ ). All the DSBs were identified as paternally derived because no $\gamma \mathrm{H} 2 \mathrm{AX}$ expression was observed from the maternal chromosome contained for H3K9me3. Considering these results together, we suggest that although the DNA damage in the $\mathrm{NaOH}$-treated spermatozoa was significant compared with that in the fresh spermatozoa, the appropriate concentration of $\mathrm{NaOH}$ treatment still maintained a low level of abnormalities compared with those generated any other methods used to dissolve the plasma membrane.

\section{Full-term development of embryos injected with $\mathrm{NaOH}$-treated spermatozoa}

Two-cell-stage embryos that had been injected with $\mathrm{NaOH}$-treated spermatozoa were transferred into recipient mice. Table 5 shows that $32 \%$ (20/64) of embryos injected with $1 \mathrm{mM} \mathrm{NaOH}$-treated spermatozoa and $36.7 \%(106 / 289)$ of those injected with $10 \mathrm{mM} \mathrm{NaOH}$ treated spermatozoa supported full-term development, whereas only $6 \%(5 / 98)$ of those injected with $20 \mathrm{mM}$ $\mathrm{NaOH}$-treated spermatozoa did so. All the offspring survived and were healthy. To examine whether the offspring remained fertile, we randomly selected a few offspring and mated them with normal ICR partners. As shown in Table 6, all offspring tested grew to adulthood and demonstrated their reproductive ability within three months after birth. These data indicate that although $10 \mathrm{mM}$ alkali medium can completely reduce the fertility of spermatozoa, oocytes injected with these spermatozoa still retain their developmental potential after artificial activation.

Table 4 Chromosome abnormalities in two-cell-stage embryos injected with differently treated spermatozoa.

\begin{tabular}{|c|c|c|c|c|c|}
\hline \multirow[b]{2}{*}{ Type of spermatozoa } & \multirow[b]{2}{*}{$\begin{array}{l}\text { No. of embryos } \\
\text { examined }\end{array}$} & \multirow[b]{2}{*}{$\begin{array}{l}\text { No. of embryos arrested } \\
\text { at } 1 \text {-cell stage }(\%)\end{array}$} & \multicolumn{3}{|c|}{ No. of zygotes developed to 2-cell stage } \\
\hline & & & Embryos & $\gamma \mathrm{H} 2 \mathrm{AX}$ posi $(\%)$ & Normal embryos (\%) \\
\hline Fresh & 42 & 0 & 42 & $3(7.1)$ & 39 (92.9) \\
\hline Heat-treated & 24 & $1(4.2)$ & 23 & $10(41.6)$ & $13(54.2)$ \\
\hline Freeze-thawed & 24 & $5(20.8)$ & 19 & 9 (37.5) & $10(41.7)$ \\
\hline $1 \mathrm{mM} \mathrm{NaOH}$ & 33 & $6(18.2)$ & 27 & $12(36.3)$ & $15(45.5)$ \\
\hline $10 \mathrm{mM} \mathrm{NaOH}$ & 39 & $3(7.7)$ & 36 & $11(28.2)$ & $25(64.1)$ \\
\hline $20 \mathrm{mM} \mathrm{NaOH}$ & 38 & $16(42.1)$ & 22 & $9(23.7)$ & $13(34.2)$ \\
\hline $50 \mathrm{mM} \mathrm{NaOH}$ & 41 & 38 (92.7) & 3 & $3(7.3)$ & 0 \\
\hline
\end{tabular}




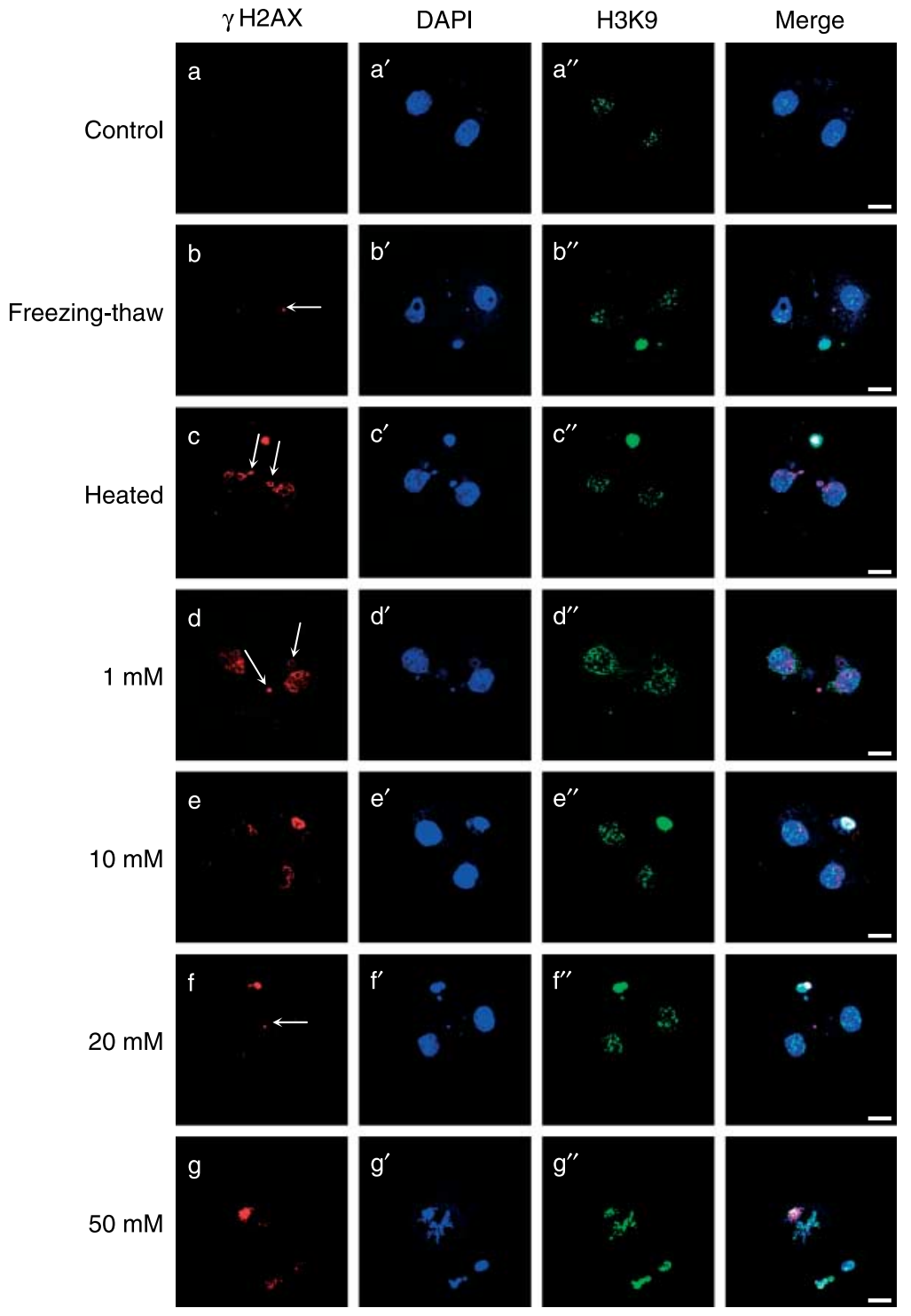

Figure 7 DSBs in embryos produced by ICSI with $\mathrm{NaOH}$ treated spermatozoa, stained for $\gamma \mathrm{H} 2 \mathrm{AX}$. The two-cellstage zygotes, which had been injected with different concentrations of $\mathrm{NaOH}$-treated, freeze-thawed or heattreated spermatozoa, were stained for the DSB marker $\gamma \mathrm{H} 2 \mathrm{AX}(\mathrm{a}-\mathrm{g})$, DAPI $\left(\mathrm{a}^{\prime}-\mathrm{g}^{\prime}\right)$ or H3K9me3 $\left(\mathrm{a}^{\prime \prime}-\mathrm{g}^{\prime \prime}\right)$. Oocytes injected with fresh (a), freeze-thawed (b), heat-treated (c) or $\mathrm{NaOH}$-treated spermatozoa (1 mM (d), $10 \mathrm{mM}$ (e), $20 \mathrm{mM}(\mathrm{f}), 50 \mathrm{mM}(\mathrm{g}))$. Arrow shows an ACS zygote, which is stained for $\gamma \mathrm{H} 2 \mathrm{AX}$. The numbers of zygotes examined are shown in Table 4. $a-g^{\prime \prime}$, scale bar $=20 \mu \mathrm{m}$.

\section{Discussion}

In this study, we examined the nuclear integrity and the developmental potential of spermatozoa treated with highly alkaline medium. The concentration of $\mathrm{NaOH}$ was very important in the treatment of spermatozoa; $10 \mathrm{mM}$ $\mathrm{NaOH}$ dissolved the membrane and destroyed the SOAF of the spermatozoa, and separated the tail from the head, so that ICSI could be performed easily. Moreover, 36.7\% healthy pups were delivered after embryo transfer into recipient mice, and all of them maintained a normal reproductive capacity.

\section{'Dead' spermatozoa after treatment with $\mathrm{NaOH}$ still retain developmental potential}

Our data show that after treatment with $\mathrm{NaOH}$, all spermatozoa lost their motility, and all $\mathrm{NaOH}$-treated spermatozoa were 'dead' according to the live/dead assay (Fig. 1e-h). However, the plasma membrane and acrosome are not essential to support normal embryonic development. So far, two types of treated spermatozoa have been reported that can still support normal embryonic development after ICSI. Type I has no membrane but retains its activation capacity, as do frozen spermatozoa and freeze-dried spermatozoa (Wakayama \& Yanagimachi 1998, Wakayama et al. 1998, Ogonuki et al. 2006). Type II has no membrane or SOAF, like heat-treated spermatozoa, LL and pronase treated spermatozoa, round spermatids, and ATABtreated spermatozoa (Ogura et al. 1994, Kimura \& Yanagimachi 1995b, Ward et al. 1999, Cozzi et al. 2001, Yan et al. 2008). In the present study, we suggested that treatment of spermatozoa with $\mathrm{NaOH}$ results in the increased full-term development compared with other methods. The phenotype of zygotes can be divided into the above two types after treating with different 
Table 5 Full-term development from $\mathrm{NaOH}$-treated spermatozoa after artificial activation.

\begin{tabular}{|c|c|c|c|c|c|c|}
\hline Medium & $\begin{array}{l}\text { No. of oocytes } \\
\text { survived } \\
\text { (no. of replicates) }\end{array}$ & $\begin{array}{l}\text { No. of oocytes } \\
\text { activated }(\%)^{\mathrm{a}}\end{array}$ & $\begin{array}{l}\text { No. of two-cell } \\
\text { embryos }(\%)^{b}\end{array}$ & $\begin{array}{l}\text { No. of embryos } \\
\text { transferred } \\
\text { (recipients) }\end{array}$ & No. of offspring $(\%)^{\mathrm{C}}$ & $\begin{array}{l}\text { No. of implanted } \\
\text { embryos }(\%)^{c}\end{array}$ \\
\hline HEPES-CZB & $124(8)$ & $124(100)$ & $116(93.5)$ & $109(8)$ & $52(48)^{*}$ & $\mathrm{~N} / \mathrm{A}$ \\
\hline $1 \mathrm{mM} \mathrm{NaOH}$ & $75(3)$ & 75 (100) & 64 (85.3) & $64(6)$ & $20(32)^{*}$ & $28(43.8)$ \\
\hline $10 \mathrm{mM} \mathrm{NaOH}$ & $352(11)$ & $344(97.7)$ & 295 (85.8) & $289(22)$ & $106(36.7)^{*}$ & 169 (58.5) \\
\hline $20 \mathrm{mM} \mathrm{NaOH}$ & $175(7)$ & $173(98.9)$ & 98 (56.0) & $98(7)$ & $5(6)^{+}$ & $11(11.2)$ \\
\hline $50 \mathrm{mM} \mathrm{NaOH}$ & $113(4)$ & $84(74.3)$ & $16(14.2)$ & $16(4)$ & $0^{+}$ & 0 \\
\hline
\end{tabular}

Significant difference between ${ }^{*}$ and ${ }^{\dagger}(P<0.01)$.

${ }^{a}$ Compared with surviving oocytes. ${ }^{b}$ Compared with activated oocytes. ${ }^{c}$ Compared with the number of transferred oocytes.

concentrations of $\mathrm{NaOH}$. Spermatozoa treated by weak alkaline $(1 \mathrm{mM} \mathrm{NaOH} \mathrm{pH:} 8.8)$ retains the fertility after ICSI (Table 1 and Fig. 2b-b"), which has already been demonstrated in freeze-dry experiments (Kaneko et al. 2003). On the other hand, high alkali $(10 \mathrm{mM} \mathrm{NaOH}$ $\mathrm{pH}: 11.3)$ treated spermatozoa were similar to the type II because high $\mathrm{pH}$ treatment completely destroyed the plasma membrane of spermatozoa (Fig. 1i-l), and these spermatozoa cannot cause oocyte activation naturally (Table 1 and Fig. $2 \mathrm{c}-\mathrm{e}^{\prime}$ ). These results are similar to a previous report by Kim et al. who showed that $100 \mathrm{mM}$ $\mathrm{NaOH}$-treated porcine spermatozoa lose fertility. It has also been reported that PLC $\zeta$, which is regarded as an important spermatozoan factor that activates the development of the oocyte (Swann et al. 2006), is inhibited by high alkaline treatment (Kurokawa et al. 2005); however, there was no evidence that the loss of PLCY reduced the developmental rate of the spermatozoa, when we used strontium to artificially activate oocytes, as normal male and female pronuclei were formed, as assessed by immunostaining (Table 2 and Fig. 3a-e). In type II treated spermatozoa, although embryonic development can be rescued using artificial activation, the full-term development rate was significantly low. To our surprise, $36.7 \%$ of transferred embryos using $\mathrm{NaOH}$-treated spermatozoa developed to full-term, which is three times higher than that by heated spermatozoa (12.5\%; Cozzi et al. 2001) and, two times higher than that by LL and pronase treated spermatozoa (17\%; Yan et al. 2008). After mating with ICR partners, all of the offspring from $\mathrm{NaOH}$-treated spermatozoa retained reproductive ability (Table 6).

Table 6 The fertility of the offspring from $\mathrm{NaOH}$-treated spermatozoa.

\begin{tabular}{llcc}
\hline Offspring ID no. & $\begin{array}{l}\text { Gender of } \\
\text { the offspring }\end{array}$ & No. of pups born & $\begin{array}{c}\text { Sex ratio } \\
(\mathrm{M} / \mathrm{F})\end{array}$ \\
\hline 1 & Male & 13 & $5 / 8$ \\
2 & Male & 9 & $6 / 3$ \\
3 & Male & 16 & $7 / 9$ \\
4 & Male & 8 & $3 / 5$ \\
5 & Female & 15 & $8 / 7$ \\
6 & Female & 14 & $6 / 8$ \\
7 & Female & 11 & $4 / 7$ \\
8 & Female & 12 & $7 / 5$ \\
\hline
\end{tabular}

We suggest that the offspring of $\mathrm{NaOH}$-treated spermatozoa are not different from those stemming from fresh spermatozoa.

\section{Chromosome damage in $\mathrm{NaOH}$-treated spermatozoa}

In the present study, compared with the fresh spermatozoa, the offspring success rate was somewhat low (36.7 vs $48 \%$ ) which may be due to some extent chromosomal damage by high $\mathrm{pH}$. In general, a highly alkaline environment can convert double-stranded chromosomal DNA into ssDNA (Mala et al. 1999). Moreover, it has been reported that a surprisingly large number of ssDNA breaks can be detected after high-alkaline treatment (Singh et al. 1989); thus, the assessment of the chromosomal DNA integrity of spermatozoa treated with various concentrations of $\mathrm{NaOH}$ becomes crucial. $\mathrm{AO}$ staining is an easy method with which to assess the proportion of ssDNA in abnormal spermatozoa (Tejada et al. 1984, Hammadeh et al. 2001). Based on AO staining, 1 and $10 \mathrm{mM} \mathrm{NaOH}$-treated spermatozoa showed normal double-stranded DNA structures, like those of fresh spermatozoa, whereas in 50 and $100 \mathrm{mM}$ $\mathrm{NaOH}$-treated spermatozoa, ssDNA (red fluorescence) was apparent (Fig. 2a-e $\mathrm{e}^{\prime \prime}$ ). DSBs in the spermatozoal chromosome are another form of DNA damage that influences normal embryonic development (Derijck et al. 2006, 2008). In this study, both karyotype analysis and immunostaining for the DSB marker, $\gamma \mathrm{H} 2 \mathrm{AX}$, showed that 1 and $10 \mathrm{mM} \mathrm{NaOH}$-treated spermatozoa had more chromosomal fragments and DSBs than those observed in fresh spermatozoa. However, more highly alkaline medium led to significantly more severe damage, which must have certainly resulted in injury to the spermatozoal DNA and explains why no embryos reached the $M / B$ stage and no offspring were produced with $50 \mathrm{mM} \mathrm{NaOH}$-treated spermatozoa (Table 2). This indicates that the alkali treatments destroyed a part of the spermatozoal developmental capacity and this was concentration dependent.

Although in the TEM images of $\mathrm{NaOH}$-treated spermatozoa the phenotype is similar to those of ATABtreated, heat-treated and freeze-dried spermatozoa (Tejada et al. 1984, Wakayama \& Yanagimachi 1998, Ward et al. 1999, Cozzi et al. 2001), the percentage of 
abnormal chromosomes in the $\mathrm{NaOH}$-treated spermatozoa was still low compared with $63 \%$ in heat-treated spermatozoa and $51 \%$ in freeze-thawed spermatozoa. Similar results were obtained with staining for $\gamma \mathrm{H} 2 \mathrm{AX}$ (Table 4 and Fig. 7). Considering these data together, we believe that the alkaline treatment of spermatozoa caused less damage than other methods, allowing safer nuclear denudation of the spermatozoa.

On the other hand, it was suggested that sperm-borne RNAs may play an important role in development and may affect the phenotype of offspring (Ostermeier et al. 2004, Rassoulzadegan et al. 2006). Recently, Yan et al. reported that the removal of perinuclear materials from spermatozoa heads using LL and pronase treatment led to a large decrease in RNA and miRNA when compared with fresh spermatozoa. Although some of those spermatozoa retained full-term developmental potential after ICSI and artificial activation, the birth rate of offspring was significantly reduced (only $17 \%$ ) when compared with offspring of fresh control spermatozoa. By contrast, in our study, $\mathrm{NaOH}$-treated spermatozoa did not lose their developmental potential, which may suggest that $\mathrm{NaOH}$ treatment has a lesser effect on RNA species. We plan to address this issue in future work.

\section{Advantages of $\mathrm{NaOH}$-treated spermatozoa and their future applications}

To date, several methods have been exploited in research into the fertilization mechanism. Freezethawing spermatozoa without cryoprotectant can remove their membranes but reduces the developmental rate to offspring. Another shortcoming is that these spermatozoa still retain their activation capacity. Heat-treated spermatozoa completely lose their SOAF, but the subsequent low offspring rate has restricted correlation analysis. The treatment of spermatozoa with ATAB seems the best method because SOAF are lost, but the normal production rate of offspring is still retained after transfer. However, this treatment is not simple and might increase the stickiness of the treated spermatozoa so that ICSI cannot be performed smoothly. The reason why our apparently harsh treatment can result in comparatively high birth rates is that other methods, which include enzyme treatment or freeze-thaw, may result not only in membrane removal but also in DNA or RNA damage. Although it is known that DNA is susceptible to alkali treatment, our results show that chromosomal damage could be suppressed to a low level via the treatment of spermatozoa using optimal alkaline conditions; therefore, this method may lead to higher birth rates when compared with others. In the present study, $\mathrm{NaOH}$-treated spermatozoa, especially those treated with $10 \mathrm{mM} \mathrm{NaOH}$, demonstrated several advantages. 1) Spermatozoa treatment is very simple, insofar as the spermatozoal suspension need only to be mixed with $\mathrm{NaOH}$ solution and then neutralized with the same concentration of $\mathrm{HCl}$ added to the medium, ensuring low cost and no need for special equipment. 2) Using this method, the spermatozoal head can be easily separated from the tail, so no Piezo pulse is required to cut the tail, which can contribute to paternal chromosome damage (Szczygiel et al. 2003, Tateno \& Kamiguchi 2007). In this study, we also showed that $1 \mathrm{mM} \mathrm{NaOH}$-treated spermatozoa, in which Piezo pulses are required to cut the sperm tail, had greater damage and a lower offspring rate than spermatozoa treated with $10 \mathrm{mM} \mathrm{NaOH}$. 3) There was only slight damage to the spermatozoal nucleus and a high rate of offspring production, all of which were healthy, including their germ cells, as demonstrated by natural mating.

The wide use of these spermatozoa in sperm preservation, and transgenesis is expected in future research. We anticipate that this method will allow the development of a novel preservation method for spermatozoa. Several methods have been developed for preserving live spermatozoa using cryoprotectants (Wakayama \& Yanagimachi 1998, Wakayama et al. 1998, Ward et al. 2003, Ogonuki et al. 2006). The difficulty in preserving live sperm is that some cryoprotectants, such as sucrose, cannot pass through the sperm membrane. However, we and others have demonstrated that the membranes of spermatozoa are not necessary for the production of offspring. If these spermatozoa are used, any cryoprotectant can be used for their longer preservation because the sperm nuclei are exposed directly to the cryoprotectant. In our study, we easily obtained naked spermatozoa with negligible nuclear damage. We intend to test whether, using this simple method, spermatozoa can be readily treated with protectant for long-term preservation.

Another application of $\mathrm{NaOH}$-treated spermatozoa is in the generation of transgenic mice. As we know, the first ICSI-mediated transgenic mouse was delivered using freeze-thawed, freeze-dried and Triton X-100-treated spermatozoa (Perry et al. 1999). However, the low rate of GFP-positive pups indicated a lethal shortcoming. To improve the success rate, several original plasmids and constructs have been designed to combine the transgene with the spermatozoa more easily (Kaneko et al. 2005, Moreira et al. 2005, Suganuma et al. 2005, Shinohara et al. 2007). However, there have been no advances in treating the spermatozoa. Here, naked spermatozoal chromosomes seemed to bind instantly to the transgene. We have already tried to use $\mathrm{NaOH}$-treated spermatozoa mixed with GFP gene to create the transgenic mice, and succeeded in getting high percentage of GFP-positive offspring (C Li, unpublished observations). This indicates great scope for future research.

On the other hand, although the birth rate was higher and the percentage of chromosome damage was lower when compared with any other methods (Table 3), some unavoidable limitations remain. Specifically, a high 
percentage of abnormal karyotypes were observed in the $\mathrm{NaOH}$-treated spermatozoa when compared with fresh spermatozoa. If this method is used for other purposes, such as human clinical applications, this high risk may be apparent; thus, at the present stage, the $\mathrm{NaOH}$ treatment method should be limited to the study of basic biology to remove the plasma membrane and activate factors in laboratory animals.

In conclusion, we have reported here for the first time the effects of high $\mathrm{pH}$ on mouse spermatozoa. Although the plasma membrane and acrosome are destroyed and the SOAF lost, the spermatozoal chromosomes still retain their developmental potential. This may be an important pretreatment method for reproductive biology.

\section{Materials and Methods}

\section{Animals}

B6D2F1 (C57BL/6) $\times$ DBA $/ 2)$ and ICR mice were obtained at 8-10 weeks of age from SLC (Hamamatsu, Japan). Transgenic mice carrying GFP (ICR background) were kindly provided by Dr Masaru Okabe (Okabe et al. 1997). All animals were maintained in accordance with the Animal Experiment Handbook at RIKEN, Center for Developmental Biology, Kobe, Japan.

\section{Media}

HEPES-buffered CZB (Kimura \& Yanagimachi 1995a) medium was used for gamete handling and ICSI in air. CZB (Chatot et al. 1989) was used for embryo culture in an atmosphere of $5 \%$ $\mathrm{CO}_{2}$ in air. $\mathrm{Ca}^{2+}$-free $\mathrm{CZB}$ containing $10 \mathrm{mM} \mathrm{SrCl}_{2}$ (Wako, Osaka, Japan) was used to activate the $\mathrm{NaOH}$-treated spermatozoa artificially (Kishigami \& Wakayama 2007). For embryo incubation, $\mathrm{CZB}$ and $\mathrm{SrCl}_{2}$-containing $\mathrm{Ca}^{2+}$-free $\mathrm{CZB}$ were overlayed with mineral oil (Wako).

\section{Collection of spermatozoa and $\mathrm{NaOH}$ treatment}

Epididymides were removed from male B6D2F1 mice. After both epididymal ducts were cut with sharp scissors, a few drops of the dense sperm mass were placed into an Eppendorf tube with $100 \mu \mathrm{L}$ HEPES-CZB and incubated for $30 \mathrm{~min}$ at $37^{\circ} \mathrm{C}$. The spermatozoa suspension $(10 \mu \mathrm{l})$ was mixed with $100 \mu \mathrm{l} 1$, $10,20,50$ or $100 \mathrm{mM} \mathrm{NaOH}$ solution (Wako) in Eppendorf tubes and was left at room temperature for $1 \mathrm{~h}$. HEPES-CZB significantly neutralized the $1 \mathrm{mM} \mathrm{NaOH}$ solution and reduced the $\mathrm{pH}$ value from 10.4 to 8.8 , whereas only a minor change in the $\mathrm{pH}$ value was observed (11.3 in $10 \mathrm{mM} \mathrm{NaOH}$-supplemented medium versus 11.5 in $10 \mathrm{mM} \mathrm{NaOH}$ solution). When the medium was supplemented with $50 \mathrm{mM}$ or $100 \mathrm{mM}$ $\mathrm{NaOH}$, there was no difference in the $\mathrm{pH}$ of the $\mathrm{NaOH}$ supplemented medium and the corresponding $\mathrm{NaOH}$ solution. The suspension was then neutralized by the same concentration of $\mathrm{HCl}$ (Wako). For the freeze-thaw treatment, $10 \mu \mathrm{l}$ spermatozoal suspension in HEPES-CZB was directly placed at $-30{ }^{\circ} \mathrm{C}$. For heat treatment, $100 \mu \mathrm{l}$ motile spermatozoal suspension in a $1.5 \mathrm{ml}$ tube was heated in a water bath for $30 \mathrm{~min}$ at $58{ }^{\circ} \mathrm{C}$. The treated spermatozoa were used for analysis and ICSI. In a few control experiments, the spermatozoa collected from GFP-ICR mice were used to confirm the experimental procedure.

\section{Oocyte preparation}

Female B6D2F1 mice were caused to superovulate by the injection of $5 \mathrm{IU}$ equine chorionic gonadotropin, followed $48 \mathrm{~h}$ later by $5 \mathrm{IU}$ of human chorionic gonadotropin (hCG). Fourteen to sixteen hours after injecting hCG, cumulus-oocyte complexes (COCs) were collected from the oviducts and moved into HEPES-CZB in a Falcon dish. To disperse the cumulus, the COCs were transferred into a HEPES-CZB drop containing $0.1 \%$ bovine testicular hyaluronidase (Sigma Chemical Co.) for $3 \mathrm{~min}$. The cumulus-free oocytes were washed twice and then moved to a new CZB droplet for culture.

\section{ICSI and embryos transfer}

To inject fresh spermatozoa, $\sim 1 \mu \mathrm{l}$ of the incubated spermatozoal suspension was mixed with a drop of HEPES-CZB containing $10 \%(\mathrm{w} / \mathrm{v})$ polyvinylpyrrolidone (PVP; Irvine Scientific, Santa Ana, CA, USA). The sperm head was separated from the tail by the application of several Piezo pulses, and the head was then injected into the oocyte according to the method described by Kimura \& Yanagimachi (1995a). To inject the $\mathrm{NaOH}$-treated spermatozoa, $2 \mu \mathrm{l}$ spermatozoal suspension was moved into another HEPES-CZB-PVP drop. Several spermatozoa heads were picked up and moved into a new HEPES-CZB-PVP drop for washing and were then injected into oocytes with the same method. The sperm suspension was replaced every $30 \mathrm{~min}$ during the ICSI experiment. The oocytes that survived after ICSI were incubated in CZB medium at $37^{\circ} \mathrm{C}$ under an atmosphere of $5 \% \mathrm{CO}_{2}$. For the oocytes injected with $\mathrm{NaOH}$-treated and heated spermatozoa, a $\mathrm{Ca}^{2+}$-free $\mathrm{CZB}$ medium containing $10 \mathrm{mM} \mathrm{SrCl} \mathrm{S}_{2}$ was used to artificially activate these oocytes. Twenty microliters of $100 \mathrm{mM} \mathrm{SrCl}_{2}$ stock solution dissolved in distilled water (stored at RT) was added to the $180 \mu \mathrm{l} \mathrm{Ca}^{2+}$-free CZB medium. Oocytes were incubated for at least 15 min after collection in the CZB media and were then placed in the activation medium for $1 \mathrm{~h}$. After washing twice, oocytes were transferred to the CZB medium to resume incubation. Parthenogenetic activation was induced using the same activation medium in the presence of $5 \mu \mathrm{g} / \mathrm{ml}$ cytochalasin B.

ICR mice were used as the recipients of the embryos. Two-cell-stage zygotes were transferred to a day 0.5 pseudopregnant mouse, which had been mated with a vasectomized male the night before transfer. Six to ten embryos were transferred into each oviduct. At day 18.5, the offspring were delivered by caesarean section and allowed to mature.

\section{Live/dead assay}

The LIVE/DEAD Sperm Viability Kit (Molecular Probes Inc., Eugene, OR, USA) was used to analyze the viability of the spermatozoa. The procedures were performed according to the 
manufacturer's protocol. Briefly, fresh spermatozoa and $\mathrm{NaOH}$-treated spermatozoa were washed three times with HEPES-CZB. A 50-fold dilution of the SYBR 14 stock solution (component A) was prepared in HEPES-CZB just before use. Diluted SYBR 14 dye $(5 \mu \mathrm{l})$ was added to a $1 \mathrm{ml}$ sample of spermatozoa, which was then incubated for $10 \mathrm{~min}$ at $37^{\circ} \mathrm{C}$. Propidium iodide ( $5 \mu \mathrm{l}$, component B) was then added to the $1 \mathrm{ml}$ sample of spermatozoa, to a final propidium iodide concentration of $12 \mu \mathrm{M}$, and incubated for a further $10 \mathrm{~min}$. An aliquot $(10 \mu \mathrm{l})$ of the spermatozoa sample was moved onto a glass slide (Matsunami, Osaka, Japan). The sample was observed under a BX51 fluorescence microscope (Olympus) equipped with a $488 \mathrm{~nm}$ filter. Images were captured with an Olympus DP70 digital camera.

\section{Transmission electron microscopy}

Fresh sperm suspension $(200 \mu \mathrm{l})$ and neutralized $\mathrm{NaOH}$-treated sperm suspension, as described above, were examined to assess the damage to the cell membrane. TEM analysis was performed by the Electron Microscope Laboratory, RIKEN, Center for Developmental Biology, Kobe, Japan.

\section{AO staining}

The AO staining method was based on previous reports (Tejada et al. 1984, Hammadeh et al. 2001). Each sample was prepared by spreading a $5 \mu \mathrm{l}$ sample of spermatozoa onto slide glass and air drying it, before it was fixed in Carnoy's solution (methanol:glacial acetic acid =3:1) overnight at room temperature. AO (Sigma Chemical Co.) was diluted to $1 \mathrm{~g} / \mathrm{l}$ and stored at $4{ }^{\circ} \mathrm{C}$ in the darkness. The buffer solution contained $40 \mathrm{ml}$ $0.1 \mathrm{M}$ citric acid (Wako) and $2.5 \mathrm{ml} 0.3 \mathrm{M} \mathrm{Na}_{2} \mathrm{HPO}_{4}$ (Wako). Diluted AO solution $(10 \mathrm{ml})$ was mixed with buffer, at a final $\mathrm{pH}$ of 2.5. The slide glass was placed into the staining solution for $5 \mathrm{~min}$ in the darkness, gently rinsed with deionized water, and mounted with VectaShield Mounting Medium for fluorescence (Vector, Burlingame, CA, USA). The samples were observed by phase-contrast microscopy with 488 and $530 \mathrm{~nm}$ excitation filters, using an Olympus BX51 fluorescence microscope, and the images were captured with an Olympus DP70 digital camera.

\section{TUNEL staining}

The In situ Apoptosis Detection Kit (Takara Bio, Shiga, Japan) was used to analyze the DNA fragmentation of the spermatozoal chromosomes. The procedures were performed according to the manufacturer's protocol. The $\mathrm{NaOH}$-treated spermatozoa were washed three times with PBS (Sigma Chemical Co.), spotted onto slide glass, air dried and fixed with $4 \%$ paraformaldehyde-PBS (Wako) for $30 \mathrm{~min}$ at ambient temperature. The samples were then treated with permeabilization buffer for $5 \mathrm{~min}$ on ice. As a positive control, spermatozoa were treated with $100 \mu \mathrm{g} / \mathrm{ml}$ DNasel in buffer $(50 \mathrm{mM}$ Tris $/ \mathrm{HCl}$ (pH 7.4; Nacalai, Kyoto, Japan), $5 \mathrm{mM} \mathrm{MgSO}_{4}$ (Wako), $0.25 \mathrm{M}$ sucrose (Wako)) for $1 \mathrm{~h}$ at $37^{\circ} \mathrm{C}$. The spermatozoa were covered with the reaction solution $(5 \mu \mathrm{l}$ terminal deoxynucleotidyl transferase, $45 \mu$ l labelling safe buffer), reacted for $90 \mathrm{~min}$ at $37^{\circ} \mathrm{C}$, and the reaction was terminated by washing with $1 \%$ BSA-PBS. The samples were treated with HRP-conjugated anti-FITC antibody at $37^{\circ} \mathrm{C}$, washed, and stained with DAB$\mathrm{H}_{2} \mathrm{O}_{2}(50 \mathrm{mg} / \mathrm{l}$ DAB in Tris- $\mathrm{HCl}(\mathrm{pH} \mathrm{7.6}), 0.1 \mathrm{ml}$ of $0.3 \%$ hydrogen peroxide) for $10 \mathrm{~min}$. The slides were washed and observed by phase-contrast and bright-field microscopy using an Olympus BX51 microscope. Data were captured with an Olympus DP70 digital camera.

\section{Karyotype analysis}

After ICSI, the fertilized oocytes were cultured for $6 \mathrm{~h}$ at $37^{\circ} \mathrm{C}$ and then transferred into CZB containing $0.006 \mu \mathrm{g} / \mathrm{ml}$ vinblastine (Sigma Chemical Co.) to arrest the oocytes at the $M$ phase of the cell cycle. Culture was continued for $14 \mathrm{~h}$, and then the zygotes were treated with acid tyrode solution to remove the zona pellucidae. The oocytes were then fixed with hypotonic solution (mixed with equal volumes of $1 \%$ sodium citrate (Wako) and 30\% foetal bovine serum (Sigma Chemical Co.)) for $10 \mathrm{~min}$ at room temperature. The oocytes were then spread onto a slide glass, according to the gradual fixation/airdrying method described previously (Mikamo \& Kamiguchi 1983). The samples were stained with $2 \%$ Giemsa (Merck) in PBS. The stained chromosomes were observed by brightfield microscopy using a BX41 microscope (Olympus). Normal zygotes were considered to contain 40 metaphase chromosomes.

\section{Immunofluorescence microscopy}

Pronucleus-stage and two-cell-stage embryos were fixed in $4 \%$ paraformaldehyde-PBS for $30 \mathrm{~min}$, washed twice with $1 \%$ BSA-PBS, and transferred into 1\% BSA-PBS containing $0.1 \%$ Triton X-100 (Nacalai) and incubated overnight at $4{ }^{\circ} \mathrm{C}$. The oocytes were then rinsed twice with 1\% BSA-PBS and incubated with the primary antibody at room temperature for $2 \mathrm{~h}$. Here, the primary antibodies used were rabbit polyclonal antibody directed against histone $\mathrm{H} 3$ (trimethyl K9; ChIP grade; ab8898, Abcam), purified mouse anti-tubulin (BD Biosciences, San Jose, CA, USA), and anti-phospho-histone (Ser139; Upstate, Temecula, CA, USA). After the embryos had been washed twice in 1\% BSA-PBS for $15 \mathrm{~min}$ each, they were incubated for $1 \mathrm{~h}$ with fluorochrome-conjugated secondary antibodies: Alexa-Fluor-488-labeled chicken antirabbit IgG (Molecular Probes Inc.) or Alexa-Fluor-568-labeled goat anti-mouse IgG (Molecular Probes Inc). The embryos were washed, and their DNA was stained with 4, 6-diamidino-2-phenylindole $(2 \mu \mathrm{g} / \mathrm{ml}$; Molecular Probes Inc). Finally, the embryos were washed twice and mounted on slides with VectaShield Mounting Medium. All the embryos were observed with a confocal scanning laser microscope (FV-1000, Olympus).

\section{Declaration of interest}

The authors declare that there is no conflict of interest that could be perceived as prejudicing the impartiality of the research reported. 


\section{Funding}

Financial support for this research was provided by a Scientific Research in Priority Areas (15080211), a grant under the Young Scientists B scheme (19780213) and a project for the realization of regenerative medicine to Teruhiko Wakayama.

\section{Acknowledgements}

We thank M Yoshizawa, H Ohta, K Yamagata, M Brahmajosyula, $\mathrm{T}$ Oyanagi and $\mathrm{Y}$ Sakaide for preparing this manuscript. We are grateful to the Laboratory for Animal Resources and Genetic Engineering of RIKEN-KOBE Center for housing the mice. Also, we thank S Yonemura in the Electron Microscope Laboratory, RIKEN, Center for Developmental Biology, Kobe, Japan for excellent assistance in the TEM imaging.

\section{References}

Birnboim HC \& Doly J 1979 A rapid alkaline extraction procedure for screening recombinant plasmid DNA. Nucleic Acids Research 7 1513-1523.

Bos-Mikich A, Whittingham DG \& Jones KT 1997 Meiotic and mitotic $\mathrm{Ca}^{2+}$ oscillations affect cell composition in resulting blastocysts. Developmental Biology 182 172-179.

Chatot CL, Ziomek CA, Bavister BD, Lewis JL \& Torres I 1989 An improved culture medium supports development of random-bred 1-cell mouse embryos in vitro. Journal of Reproduction and Fertility 86 679-688

Cozzi J, Monier-Gavelle F, Lievre N, Bomsel M \& Wolf JP 2001 Mouse offspring after microinjection of heated spermatozoa. Biology of Reproduction 65 1518-1521.

Derijck AA, van der Heijden GW, Giele M, Philippens ME, van Bavel CC \& de Boer $\mathbf{P} 2006 \gamma \mathrm{H} 2 \mathrm{AX}$ signalling during sperm chromatin remodelling in the mouse zygote. DNA Repair 5 959-971.

Derijck A, van der Heijden G, Giele M, Philippens M \& de Boer P 2008 DNA double-strand break repair in parental chromatin of mouse zygotes, the first cell cycle as an origin of de novo mutation. Human Molecular Genetics 17 1922-1937.

Goto K, Kinoshita A, Takuma Y \& Ogawa K 1990 Fertilisation of bovine oocytes by the injection of immobilised, killed spermatozoa. Veterinary Record 127 517-520.

Hammadeh ME, Greiner S, Rosenbaum P \& Schmidt W 2001 Comparison between human sperm preservation medium and TEST-yolk buffer on protecting chromatin and morphology integrity of human spermatozoa in fertile and subfertile men after freeze-thawing procedure. Journal of Andrology 22 1012-1018.

Hoshi K, Yanagida K, Yazawa H, Katayose H \& Sato A 1995 Intracytoplasmic sperm injection using immobilized or motile human spermatozoon. Fertility and Sterility 63 1241-1245.

Jiang MX, Zhu Y, Zhu ZY, Sun QY \& Chen DY 2005 Effects of cooling, cryopreservation and heating on sperm proteins, nuclear DNA, and fertilization capability in mouse. Molecular Reproduction and Development 72 129-134.

Kaneko T, Whittingham DG \& Yanagimachi R 2003 Effect of $\mathrm{pH}$ value of freeze-drying solution on the chromosome integrity and developmental ability of mouse spermatozoa. Biology of Reproduction $\mathbf{6 8}$ 136-139.

Kaneko T, Moisyadi S, Suganuma R, Hohn B, Yanagimachi R \& Pelczar P 2005 Recombinase-mediated mouse transgenesis by intracytoplasmic sperm injection. Theriogenology 64 1704-1715.

Kim NH, Jun SH, Do JT, Uhm SJ, Lee HT \& Chung KS 1999 Intracytoplasmic injection of porcine, bovine, mouse, or human spermatozoon into porcine oocytes. Molecular Reproduction and Development 53 84-91.

Kimura Y \& Yanagimachi R 1995a Intracytoplasmic sperm injection in the mouse. Biology of Reproduction 52 709-720.
Kimura Y \& Yanagimachi R 1995b Mouse oocytes injected with testicular spermatozoa or round spermatids can develop into normal offspring. Development 121 2397-2405.

Kishigami S \& Wakayama T 2007 Efficient strontium-induced activation of mouse oocytes in standard culture media by chelating calcium. Journal of Reproduction and Development 53 1207-1215.

Kishigami S, Thuan NV, Wakayama S, Hikichi T \& Wakayama T 2004 A novel method for isolating spermatid nuclei from cytoplasm prior to ROSI in the mouse. Zygote 12 321-327.

Kuretake S, Kimura Y, Hoshi K \& Yanagimachi R 1996 Fertilization and development of mouse oocytes injected with isolated sperm heads. Biology of Reproduction 55 789-795.

Kurokawa M, Sato K, Wu H, He C, Malcuit C, Black SJ, Fukami K \& Fissore RA 2005 Functional, biochemical, and chromatographic characterization of the complete $\left[\mathrm{Ca}^{2+}\right]_{i}$ oscillation-inducing activity of porcine sperm. Developmental Biology 285 376-392.

Kwon IK, Park KE \& Niwa K 2004 Activation, pronuclear formation, and development in vitro of pig oocytes following intracytoplasmic injection of freeze-dried spermatozoa. Biology of Reproduction $\mathbf{7 1}$ 1430-1436.

Lawitts JA \& Biggers JD 1991 Optimization of mouse embryo culture media using simplex methods. Journal of Reproduction and Fertility 91 543-556.

Liu JL, Kusakabe H, Chang CC, Suzuki H, Schmidt DW, Julian M, Pfeffer R, Bormann CL, Tian XC, Yanagimachi R et al. 2004 Freeze-dried sperm fertilization leads to full-term development in rabbits. Biology of Reproduction 70 1776-1781.

Mala Z, Kleparnik K \& Bocek P 1999 Highly alkaline electrolyte for singlestranded DNA separations by electrophoresis in bare silica capillaries. Journal of Chromatography 853 371-379.

Mikamo K \& Kamiguchi Y 1983 A new assessment system for chromosomal mutagenicity using oocytes and early zygotes of the Chinese hamster. In Radiation-Induced Chromosome Damage in Man, pp 411-432. Eds T Ishihara \& MS Sasaki. New York: Alan R Liss.

Moreira PN, Fernandez-Gonzalez R, Rizos D, Ramirez M, Perez-Crespo M \& Gutierrez-Adan A 2005 Inadvertent transgenesis by conventional ICSI in mice. Human Reproduction 20 3313-3317.

Nagy ZP, Liu J, Joris H, Verheyen G, Tournaye H, Camus M, Derde MC, Devroey P \& Van Steirteghem AC 1995 The result of intracytoplasmic sperm injection is not related to any of the three basic sperm parameters. Human Reproduction 10 1123-1129.

Ogonuki N, Mochida K, Miki H, Inoue K, Fray M, Iwaki T, Moriwaki K, Obata Y, Morozumi K, Yanagimachi R et al. 2006 Spermatozoa and spermatids retrieved from frozen reproductive organs or frozen whole bodies of male mice can produce normal offspring. PNAS 103 13098-13103.

Ogura A, Matsuda J \& Yanagimachi R 1994 Birth of normal young after electrofusion of mouse oocytes with round spermatids. PNAS 91 7460-7462.

Okabe M, Ikawa M, Kominami K, Nakanishi T \& Nishimune Y 1997 'Green mice' as a source of ubiquitous green cells. FEBS Letters 407 313-319.

Ostermeier GC, Miller D, Huntriss JD, Diamond MP \& Krawetz SA 2004 Reproductive biology: delivering spermatozoan RNA to the oocyte. Nature 429154.

Parrington J, Jones ML, Tunwell R, Devader C, Katan M \& Swann K 2002 Phospholipase $\mathrm{C}$ isoforms in mammalian spermatozoa: potential components of the sperm factor that causes $\mathrm{Ca}^{2+}$ release in eggs. Reproduction 123 31-39.

Perry AC, Wakayama T, Kishikawa H, Kasai T, Okabe M, Toyoda Y \& Yanagimachi R 1999 Mammalian transgenesis by intracytoplasmic sperm injection. Science 284 1180-1183.

Quinn P, Barros C \& Whittingham DG 1982 Preservation of hamster oocytes to assay the fertilizing capacity of human spermatozoa. Journal of Reproduction and Fertility 66 161-168.

Rassoulzadegan M, Grandjean V, Gounon P, Vincent S, Gillot I \& Cuzin F 2006 RNA-mediated non-mendelian inheritance of an epigenetic change in the mouse. Nature 441 469-474.

Saunders CM, Larman MG, Parrington J, Cox LJ, Royse J, Blayney LM, Swann K \& Lai FA 2002 PLC zeta: a sperm-specific trigger of $\mathrm{Ca}(2+)$ oscillations in eggs and embryo development. Development 129 3533-3544. 
Shinohara ET, Kaminski JM, Segal DJ, Pelczar P, Kolhe R, Ryan T, Coates CJ, Fraser MJ, Handler AM, Yanagimachi R et al. 2007 Active integration: new strategies for transgenesis. Transgenic Research $\mathbf{1 6}$ 333-339.

Singh NP, Danner DB, Tice RR, McCoy MT, Collins GD \& Schneider EL 1989 Abundant alkali-sensitive sites in DNA of human and mouse sperm. Experimental Cell Research 184 461-470.

Suganuma R, Pelczar P, Spetz JF, Hohn B, Yanagimachi R \& Moisyadi S 2005 Tn5 transposase-mediated mouse transgenesis. Biology of Reproduction 73 1157-1163.

Swann K, Saunders CM, Rogers NT \& Lai FA 2006 PLCzeta (zeta): a sperm protein that triggers $\mathrm{Ca}^{2+}$ oscillations and egg activation in mammals. Seminars in Cell and Developmental Biology 17 264-273.

Szczygiel MA, Moisyadi S \& Ward WS 2003 Expression of foreign DNA is associated with paternal chromosome degradation in intracytoplasmic sperm injection-mediated transgenesis in the mouse. Biology of Reproduction 68 1903-1910.

Tateno H \& Kamiguchi Y 2004 Chromosome analysis of mouse one-cell androgenones derived from a sperm nucleus exposed to topoisomerase II inhibitors at pre- and post-fertilization stages. Mutation Research 556 $117-126$.

Tateno H \& Kamiguchi Y 2007 Evaluation of chromosomal risk following intracytoplasmic sperm injection in the mouse. Biology of Reproduction 77 336-342.

Tateno H, Kimura Y \& Yanagimachi R 2000 Sonication per se is not as deleterious to sperm chromosomes as previously inferred. Biology of Reproduction 63 341-346.

Tejada RI, Mitchell JC, Norman A, Marik JJ \& Friedman S 1984 A test for the practical evaluation of male fertility by acridine orange (AO) fluorescence. Fertility and Sterility 42 87-91.
Wakayama T \& Yanagimachi R 1998 Development of normal mice from oocytes injected with freeze-dried spermatozoa. Nature Biotechnology 16 639-641.

Wakayama T, Whittingham DG \& Yanagimachi R 1998 Production of normal offspring from mouse oocytes injected with spermatozoa cryopreserved with or without cryoprotection. Journal of Reproduction and Fertility 112 11-17.

Ward WS, Kimura Y \& Yanagimachi R 1999 An intact sperm nuclear matrix may be necessary for the mouse paternal genome to participate in embryonic development. Biology of Reproduction 60 702-706.

Ward MA, Kaneko T, Kusakabe H, Biggers JD, Whittingham DG \& Yanagimachi R 2003 Long-term preservation of mouse spermatozoa after freeze-drying and freezing without cryoprotection. Biology of Reproduction 69 2100-2108.

Whittingham DG 1971 Culture of mouse ova. Journal of Reproduction and Fertility 14 7-21.

Yan W, Morozumi K, Zhang J, Ro S, Park C \& Yanagimachi R 2008 Birth of mice after intracytoplasmic injection of single purified sperm nuclei and detection of messenger RNAs and microRNAs in the sperm nuclei. Biology of Reproduction 78 896-902.

Yanagimachi R 2005 Intracytoplasmic injection of spermatozoa and spermatogenic cells: its biology and applications in humans and animals. Reproductive Biomedicine Online 10 247-288.

Received 14 November 2008

First decision 19 December 2008

Accepted 19 February 2009 